\title{
Comparison of Propranolol and Metoprolol on Patients with Unstable Angina Pectoris and their Effects on High-Sensitivity C-Reactive Protein, Lipoprotein Associated Phospholipase A2
}

\author{
B. ZHANG, J. ZHOU*, WENJING DAI, J. LV AND YUANLIN GUO
}

Department of Internal Cardiovascular Medicine, Renhe Hospital, China Three Gorges University, Yichang, Hubei 443000, China

Zhang et al.: Comparative Study of Propranolol and Metoprolol on Unstable Angina Pectoris

\begin{abstract}
To investigate the efficacy of propranolol and metoprolol on unstable angina pectoris patients and their effects on high-sensitivity C-reactive protein and lipoprotein associated phospholipase A2. Altogether 138 unstable angina pectoris patients admitted to our hospital were considered and enrolled into two groups in view of the treatment methods. Among them, 62 patients in the control group were treated with propranolol and 76 cases in the observation group were treated with metoprolol. The efficacy and incidence of adverse reactions of patients after treatment in both groups were recorded, and their seizure frequency and duration of angina pectoris were compared. The cardiac functions of both groups before and after treatment were compared: left ventricular ejection fraction, left ventricular end diastolic volume and left ventricular end systolic volume. Enzyme-linked immunosorbent assay was employed to examine the concentration of inflammatory factors in serum before and after treatment: serum high-sensitivity $C$-reactive protein and serum lipoprotein-associated phospholipase A2. The risk factors affecting their efficacy were assessed through logistic regression analysis. The expression of cardiac function in the observation group after treatment was dramatically better than that in the control group. The seizure frequency, duration and inflammatory factor level in the observation group after treatment were dramatically lower than those in the control group. The clinical efficacy in the observation group was obviously higher than that in the control group. There was no marked difference in incidence of adverse reactions between both groups. Multivariate logistic regression analysis identified that gender, history of diabetes, hypertension, levels of high-sensitivity C-reactive protein, lipoprotein associated phospholipase $\mathrm{A} 2$ before treatment and treatment methods were independent risk factors affecting their efficacy. Compared with propranolol, metoprolol can dramatically improve the cardiac function of unstable angina pectoris patients, control the seizure frequency and duration of angina pectoris and reduce the level of inflammatory factors.
\end{abstract}

Key words: Unstable angina pectoris, propranolol, metoprolol, high-sensitivity C-reactive protein, lipoprotein associated phospholipase A2

Unstable Angina Pectoris (UAP) is an Acute Coronary Syndrome (ACS), which is mainly caused by acute myocardial ischemia and hypoxia. It is angina pectoris between Stable Angina Pectoris (SAP) and Acute Myocardial Infarction (AMI $)^{[1]}$. Epidemiological survey data show that UAP has more than one million hospitalized patients each year, with a high morbidity and the morbidity of males is significantly higher than that of females. It progresses very rapidly and $6 \%$ to $8 \%$ of UAP patients in hospital will develop non-fatal myocardial infarction or death ${ }^{[2]}$. It is mainly developed from SAP and its pathogenesis is related to coronary atherosclerotic plaque rupture, mural thrombosis, platelet aggregation and other factors. The clinical diagnosis of UAP is usually determined by ischemic biomarkers such as cardiac troponin, electrocardiogram determination, coronary angiography and symptoms of angina pectoris ${ }^{[3]}$. Currently, clinical treatment methods for UAP include drug therapy, interventional therapy and surgical treatment ${ }^{[4]}$. Drug therapy mainly includes antithrombotic, anti-myocardial ischemia and lipid-regulating therapy ${ }^{[5]}$. However, clinical treatment

*Address for correspondence

E-mail: 3282144818@qq.com 
will increase the risk of sudden death, stroke or nonfatal myocardial infarction ${ }^{[6]}$. Although some studies show that the progress of treatment measures for cardiovascular diseases has shown a downward trend in clinical practice, due to the continuous growth of the global population aging and the high mortality, the exploration of safe and effective treatment schemes has always been a clinical research hotspot ${ }^{[7]}$.

Propranolol is a non-selective competitive inhibitor of epinephrine beta $(\beta)$ receptor blocker, which can block $\beta 1$ and $\beta 2$ receptors on the heart of UAP patients at the same time and can restore the balance of oxygen supply and demand in ischemic myocardium at a low level ${ }^{[8]}$. Studies have shown that it can be used clinically to treat arrhythmia, hypertension, angina pectoris, etc., caused by various reasons. It is soluble in water and absorbed completely after oral administration, about $90 \%\left[{ }^{[9]}\right.$. Metoprolol can competitively block $\beta 1$-adrenoceptors in glomerulus and heart and its blocking effect on $\beta 2$ receptor is very weak. Metoprolol is a selective $\beta 1$ adrenoceptor blocker ${ }^{[10]}$. Relevant studies show that it can effectively treat cardiovascular diseases such as hypertension, arrhythmia, myocardial infarction, etc. It is extremely soluble in water and can be completely absorbed by patients after oral administration ${ }^{[11]}$. Studies have shown that UAP patients can effectively reduce the occurrence of angina pectoris and prevent the risk of non-fatal myocardial infarction after receiving metoprolol treatment ${ }^{[12]}$. The results manifested that the levels of high sensitivity C-Reactive Protein (hs-CRP) and serum Lipoprotein-related Phospholipase A2 (LpPLA2) in UAP patients increased to different degrees ${ }^{[13]}$. hs-CRP is an acute phase protein synthesized when the body is stimulated by inflammation. It rises for several hours after inflammation occurs and reaches its peak within $48 \mathrm{~h}^{[14]}$. Lp-PLA2 is a specific inflammatory factor secreted by inflammatory cells and plays a vital part in UAP's development and progression ${ }^{[15]}$. hsCRP and Lp-PLA2 can be employed as inflammatory indicators to evaluate the efficacy of UAP patients ${ }^{[16]}$. Zhong et al. pointed out that the frequency of angina pectoris and the levels of hs-CRP, Lp-PLA2 decreased after drug therapy with epinephrine $\beta$ blocker ${ }^{[17]}$.

At present, there are few researches on the comparison of clinical effects of propranolol and metoprolol in treating UAP and their effects on hs-CRP and Lp-PLA2. This study will evaluate the efficacy of the two alone and analyze their effects on hs-CRP and Lp-PLA2, hoping to provide clinical reference value for patients.

\section{MATERIALS AND METHODS}

\section{General information:}

HAltogether 138 UAP patients admitted to our hospital from June 2017 to March 2019 were regarded as the research participants. 62 cases were divided into the control group, 38 males and 24 females, aged 52-75 $y$ with an average of $(60.03 \pm 3.93) \mathrm{y}$; the course of disease was 1.1-8.5 mo, averaging (2.86 \pm 1.51$)$ mo. Cardiac function New York Heart Association (NYHA) classification was: 38 cases of class I and 24 cases of class II. 76 cases were enrolled into the observation group, 46 males and 30 females, aged 55-78 y with an average of $(59.53 \pm 4.12) \mathrm{y}$; the course of disease was 1.3-9.1 mo, with an average of (3.26 \pm 1.47$)$ mo. Cardiac function NYHA classification was: 45 cases of class I and 31 cases of class II. This study was approved by the ethics committee of our hospital. The subjects and their families have been informed and they have signed a fully informed consent form.

Inclusion criteria includes patients conformed to diagnostic criteria for UAP established by American Heart Association (AHA) ${ }^{[18]}$; UAP was confirmed by electrocardiogram (ECG) and coronary angiography; those had typical clinical symptoms of UAP; all patients were first time diagnosed as UAP; those had complete clinical data.

Exclusion criteria includes those complicated with liver and kidney dysfunction, pulmonary heart disease, severe heart failure or valvulopathy; patients; those had allergic constitution and drug allergy; a person who withdrew from an experiment in the middle of a journey or who lost an interview.

\section{Treatment methods:}

After admission, patients in both groups received routine basic treatment: antiplatelet, anticoagulant and oxygen inhalation. Control group: propranolol hydrochloride (Lisheng Pharmaceutical Co., Ltd., Tianjin, China, item number: H12020151) was taken orally, twice/d, $10 \mathrm{mg} /$ time $^{[19]}$. Observation group: metoprolol tartrate (Ruikang Pharmaceutical Co., Ltd., Sichuan, China, item number: H20084505) was taken orally, $12.5 \mathrm{mg} /$ time and 2 times $/ \mathrm{d}^{[20]}$. Patients in both groups were given continuous medication for 1 mo.

\section{Outcome measures:}

Total effective rate of treatment; Seizure frequency and duration of angina pectoris; Cardiac function indexes such as Left Ventricular Ejection Fraction (LVEF), Left Ventricular End Diastolic Volume 
(LVEDV) and Left Ventricular End Systolic Volume (LVESV); Inflammatory factors: serum Lp-PLA2 and hs-CRP levels were measured before and after admission in both groups. Both Lp-PLA2 and hs-CRP were determined via solid-phase sandwich EnzymeLinked Immunosorbent Assay (ELISA). The tests were conducted in strict conformity with the specifications of human Lp-PLA2 ELISA kit (Jingkang Bioengineering Co., Ltd., Shanghai, China, JK-EA01476) and hs-CRP ELISA kit (JK-EA00186). All testing operations were undertaken by the same professional; Incidence of adverse reactions.

\section{Evaluation standard of efficacy:}

Markedly effective-clinical symptoms completely disappear and electrocardiogram returns to normal level. Effective-the clinical symptoms are obviously improved, the pain degree is relieved, the attack times are reduced and the electrocardiogram is obviously improved but not restored to the normal level. Ineffective-There is no obvious improvement in clinical symptoms and ECG, no change or prolongation of duration, no change or aggravation of frequency.

Total effective rate $=($ number of effective cases + number of effective cases)/total number of cases $\times 100 \%$

\section{Statistical methods:}

The data were statistically analyzed via Statistical Package For The Social Sciences (SPSS) 21.0 (Beijing Bioeasy Technology Co., Ltd., China). The counting data were represented by the number of cases/percentage (n/\%) and their comparison between groups was conducted by Chi-square test. When the theoretical frequency in Chi-square test was less than
5 , we employed the continuity correction Chi-square test. The measurement data were represented by $\mathrm{X} \pm \mathrm{S}$ and their comparison of between groups was conducted through independent-sample T-test. The comparison before and after treatment within the group was conducted via paired T-test, the data above two groups were analyzed by one-way analysis of variance and the comparison between both groups was conducted by Bonferroni method. The risk factors affecting the efficacy of UAP patients were assessed via Logistics multivariate regression analysis. The difference was statistically remarkable when $\mathrm{p}<0.05$.

\section{RESULTS AND DISCUSSION}

There was no marked difference between the two groups in terms of gender, age, course of disease, NYHA classification of cardiac function, seizure type, history of diabetes, hypertension, smoking, drinking, place of residence and other clinical first-line data $(\mathrm{p}>0.05)$ (Table 1).

After treatment, the total effective rate of patients in the observation group was $96.05 \%$, while that in the control group was $77.42 \%$; the rate in the observation group was higher than that in the control group $(\mathrm{p}<0.05)$ (Table 2).

Before treatment, there was no marked difference in the seizure frequency and duration of angina pectoris between both groups. After treatment, the frequency and duration were dramatically reduced, with obvious difference compared with before treatment. In the meantime, the frequency and duration in the observation group decreased more remarkably than that in the control group (fig. 1)

TABLE 1: COMPARISON OF GENERAL DATA OF PATIENTS BETWEEN BOTH GROUPS [n (\%)] ( $\mathrm{x} \pm \mathbf{s})$

\begin{tabular}{|c|c|c|c|c|}
\hline Classification & Control group $(n=62)$ & $\begin{array}{l}\text { Observation group } \\
(n=76)\end{array}$ & $t / x^{2}$ value & $\mathrm{p}$ value \\
\hline Gender & & & 0.008 & 0.927 \\
\hline Male & $38(61.29)$ & $46(60.53)$ & & \\
\hline Female & $24(38.71)$ & $30(39.47)$ & & \\
\hline \multirow[t]{2}{*}{ Age $(y)$} & & & 0.000 & 0.999 \\
\hline & $60.03 \pm 3.93$ & $59.53 \pm 4.12$ & & \\
\hline \multirow[t]{2}{*}{ Course of disease $(\mathrm{mo})$} & & & 1.571 & 0.118 \\
\hline & $2.86 \pm 1.51$ & $3.26 \pm 1.47$ & & \\
\hline $\begin{array}{l}\text { Cardiac function NYHA } \\
\text { classification }\end{array}$ & & & 0.062 & 0.804 \\
\hline Class I & 38 (61.29) & $45(59.21)$ & & \\
\hline Class II & $24(38.71)$ & 31 (40.79) & & \\
\hline Seizure type & & & 1.057 & 0.901 \\
\hline Special Issue 5, 2021 & Indian & urnal of Pharmaceutical & & \\
\hline
\end{tabular}




\begin{tabular}{|c|c|c|c|c|}
\hline Recent onset angina & $28(45.16)$ & $32(42.11)$ & & \\
\hline $\begin{array}{l}\text { Deteriorating exertional } \\
\text { angina pectoris }\end{array}$ & $18(29.03)$ & $25(32.89)$ & & \\
\hline Resting angina pectoris & $9(14.52)$ & $13(17.10)$ & & \\
\hline $\begin{array}{l}\text { Angina pectoris after } \\
\text { myocardial infarction }\end{array}$ & $5(8.06)$ & $5(6.58)$ & & \\
\hline Variant angina pectoris & $2(3.23)$ & $1(1.32)$ & & \\
\hline History of diabetes & & & 0.177 & 0.674 \\
\hline Yes & $42(67.74)$ & $54(71.05)$ & & \\
\hline No & $20(32.26)$ & $22(28.95)$ & & \\
\hline History of hypertension & & & 0.104 & 0.747 \\
\hline Yes & $45(72.58)$ & $57(75.00)$ & & \\
\hline No & $17(27.42)$ & $19(25.00)$ & & \\
\hline History of smoking & & & 0.392 & 0.530 \\
\hline Yes & $47(75.81)$ & $54(71.05)$ & & \\
\hline No & $15(24.19)$ & $22(28.95)$ & & \\
\hline History of drinking & & & 0.151 & 0.697 \\
\hline Yes & $43(69.35)$ & $55(72.37)$ & & \\
\hline No & 19 (30.65) & $21(27.63)$ & & \\
\hline Place of residence & & & 1.042 & 0.307 \\
\hline Countryside & $38(61.29)$ & $40(52.63)$ & & \\
\hline Cities and towns & $24(38.71)$ & $36(47.37)$ & & \\
\hline
\end{tabular}

TABLE 2: EFFICACY OF PATIENTS IN BOTH GROUPS AFTER TREATMENT [n (\%)]

\begin{tabular}{lccccc}
\hline Group & $\mathrm{n}$ & Markedly effective & Effective & Ineffective & Total effective rate (\%) \\
\hline Observation group & 76 & $61(80.26)$ & $12(15.79)$ & $3(3.95)$ & $73(96.05)$ \\
Control group & 62 & $25(40.32)$ & $23(37.10)$ & $14(22.58)$ & $48(77.42)$ \\
$\mathrm{x}^{2}$ & - & - & - & - & 24.48 \\
$\mathrm{p}$ & - & $-\mathrm{xz}$ & - & - & $<0.000$ \\
\hline
\end{tabular}

A

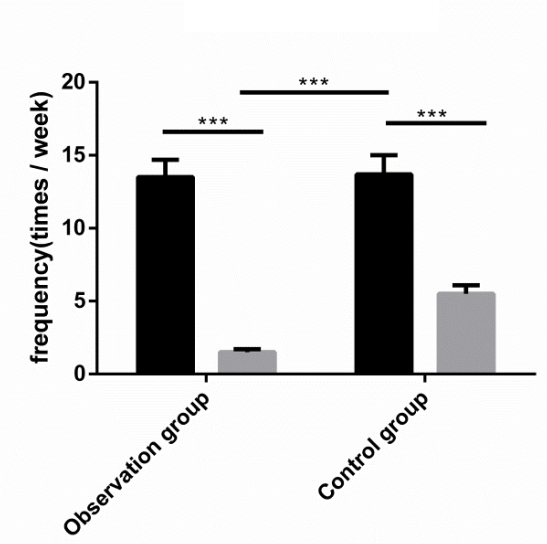

B

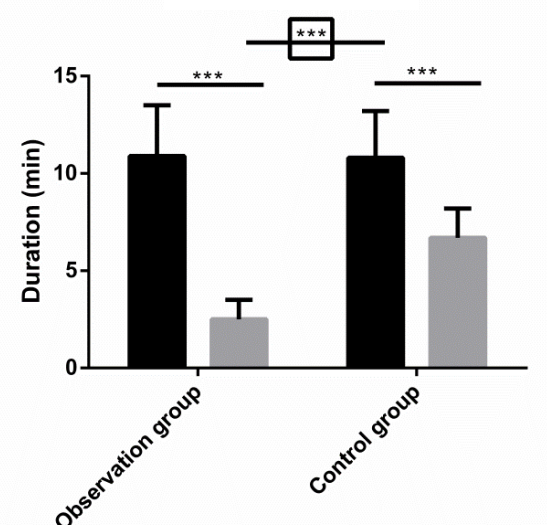

Fig. 1: Changes in seizure frequency and duration of angina pectoris before and after treatment in the two groups, (A) comparison of seizure frequency of angina pectoris before and after treatment between both groups; (B) comparison of duration of angina pectoris before and after treatment between both groups

Note: ***p $<$ 0.001. ( $(\square)$ Before treatment; $(\square)$ After treatment 
Before treatment, there was no remarkable difference in LVEF, LVEDV and LVESV between both groups. After treatment, LVEF was dramatically increased, LVEDV and LVESV were dramatically decreased and there was obvious difference compared with before treatment. Meanwhile, LVEF in the observation group increased more dramatically than that in the control group and LVEDV and LVESV decreased more obviously (fig. 2).

There was no marked difference in the hs-CRP and LpPLA2 levels between both groups before treatment. After treatment, the levels decreased. Compared with the control group, the levels in the observation group decreased more dramatically (fig. 3).

During the treatment, 2 cases of nausea and vomiting and 3 cases of dizziness occurred in the control group and the incidence of adverse reactions was $8.07 \%$. There was 1 case of nausea and vomiting and 1 case of dizziness in the observation group and the incidence was $3.95 \%$. There was no marked difference in the incidence of adverse reactions between both groups (Table 3).

We compared the differences of clinical parameters and related indexes between effective and ineffective patients. And we discovered that 121 patients were effective and 17 patients were ineffective. There was no obvious difference in age, course of disease, cardiac function NYHA classification, seizure type and place of residence of effective and ineffective patients ( $p>0.05)$, while there were statistical differences in gender, history of diabetes, hypertension, smoking, drinking, hs-CRP, Lp-PLA2 and treatment methods $(p<0.05)$. Finally, we analyzed the different factors by multivariate logistic regression. The results manifested that gender $(p=0.013)$, diabetes history $(p=0.026)$, hypertension history $(\mathrm{p}=0.029)$, hs-CRP $(\mathrm{p}=0.010)$, Lp-PLA2 $(p=0.016)$ and treatment methods $(p=0.007)$ were independent risk factors that affected the efficacy of patients (Tables 4-6).
A

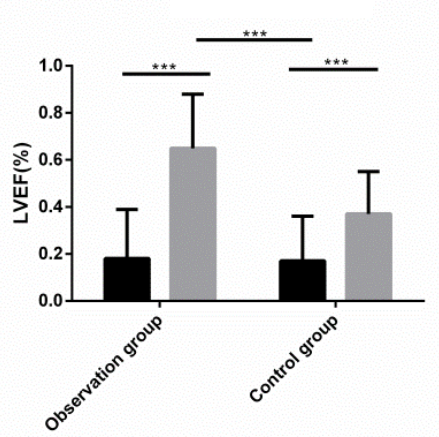

B

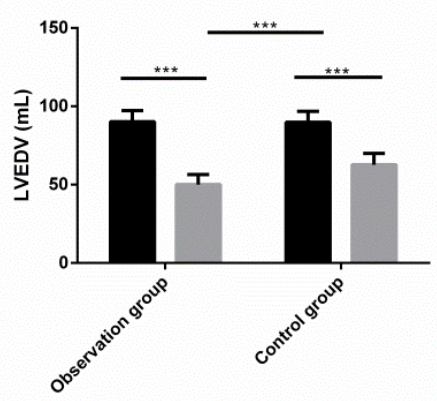

C

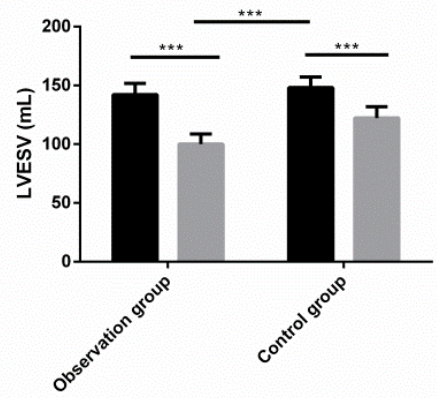

Fig. 2: Cardiac function indexes before and after treatment in the two groups, (A) comparison of LVEF before and after treatment between both groups; (B) comparison of LVEDV before and after treatment between both groups; (C) comparison of LVESV before and after treatment between both groups

Note: $* *$ p $<$ 0.001. ( $(\square)$ Before treatment; $(\square)$ After treatment

A

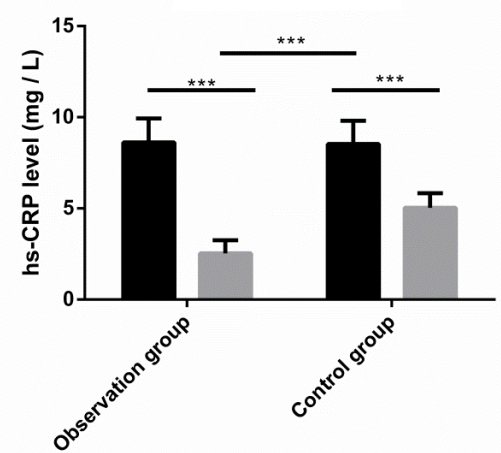

B

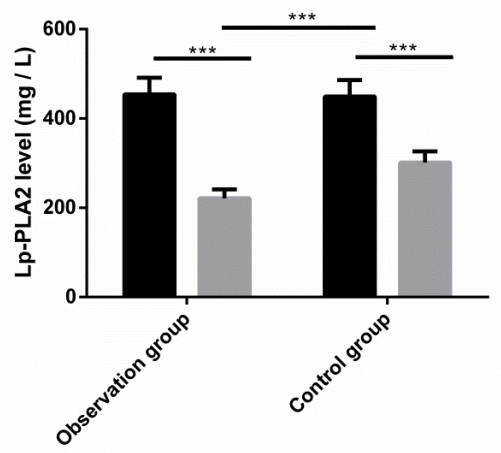

Fig. 3: Levels of inflammatory factors before and after treatment in the two groups, (A) comparison of hs-CRP levels before and after treatment between both groups; (B) comparison of Lp-PLA2 levels before and after treatment between both groups Note: $* *$ p $<0.001$. ( $\square)$ Before treatment; $(\square)$ After treatment 
TABLE 3: COMPARISON OF ADVERSE REACTIONS OF PATIENTS IN TWO GROUPS [n (\%)]

\begin{tabular}{lcccc}
\hline Group & $\mathrm{n}$ & Nausea and vomiting & Dizziness & Total incidence (\%) \\
\hline Observation group & 76 & $1(1.32)$ & $2(2.63)$ & $3(3.95)$ \\
Control group & 62 & $2(3.23)$ & $3(4.84)$ & $5(8.07)$ \\
$\chi^{2}$ & - & - & - & 0.649 \\
$\mathrm{p}$ & - & - & - & 0.42 \\
\hline
\end{tabular}

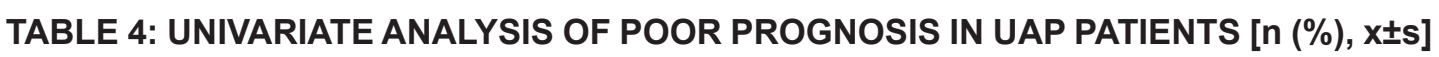

\begin{tabular}{|c|c|c|c|c|c|}
\hline Factor & $\mathrm{n}$ & $\begin{array}{l}\text { Effective group } \\
(n=121)\end{array}$ & $\begin{array}{l}\text { Ineffective group } \\
(n=17)\end{array}$ & $x^{2} / t$ & $\mathrm{p}$ \\
\hline Gender & & & & 6.096 & 0.010 \\
\hline Male & 84 & $69(82.14)$ & $15(17.86)$ & & \\
\hline Female & 54 & $52(96.30)$ & $2(3.70)$ & & \\
\hline Age $(y)$ & & & & 1.082 & 0.298 \\
\hline$<55$ & 48 & $44(91.67)$ & $4(8.33)$ & & \\
\hline$\geq 55$ & 90 & $77(85.56)$ & $13(14.44)$ & & \\
\hline \multirow[t]{2}{*}{$\begin{array}{l}\text { Course of disease } \\
\text { (mo) }\end{array}$} & & & & 1.519 & 0.131 \\
\hline & 138 & $2.51 \pm 1.40$ & $3.06 \pm 1.38$ & & \\
\hline $\begin{array}{l}\text { Cardiac function } \\
\text { NYHA classification }\end{array}$ & & & & 2.910 & 0.088 \\
\hline Class I & 83 & $76(91.57)$ & $7(8.43)$ & & \\
\hline Class II & 55 & $45(81.82)$ & $10(18.18)$ & & \\
\hline Seizure type & & & & 3.001 & 0.558 \\
\hline $\begin{array}{l}\text { Recent onset } \\
\text { angina }\end{array}$ & 60 & $52(86.67)$ & $8(13.33)$ & & \\
\hline $\begin{array}{l}\text { Deteriorating } \\
\text { exertional angina } \\
\text { pectoris }\end{array}$ & 43 & $40(93.02)$ & $3(6.98)$ & & \\
\hline $\begin{array}{l}\text { Resting angina } \\
\text { pectoris }\end{array}$ & 22 & $19(86.36)$ & $3(13.64)$ & & \\
\hline $\begin{array}{l}\text { Angina pectoris } \\
\text { after myocardial } \\
\text { infarction }\end{array}$ & 10 & $8(80.00)$ & $2(20.00)$ & & \\
\hline $\begin{array}{l}\text { Variant angina } \\
\text { pectoris }\end{array}$ & 3 & $2(66.67)$ & $1(33.33)$ & & \\
\hline History of diabetes & & & & 5.520 & 0.018 \\
\hline Yes & 96 & $80(83.33)$ & $16(16.67)$ & & \\
\hline No & 42 & $41(97.62)$ & $1(2.38)$ & & \\
\hline $\begin{array}{l}\text { History of } \\
\text { hypertension }\end{array}$ & & & & 4.105 & 0.040 \\
\hline Yes & 102 & $86(84.31)$ & $16(15.69)$ & & \\
\hline No & 36 & $35(97.22)$ & $1(2.78)$ & & \\
\hline History of smoking & & & & 4.328 & 0.037 \\
\hline Yes & 101 & $85(84.16)$ & $16(15.84)$ & & \\
\hline No & 37 & $36(97.30)$ & $1(2.70)$ & & \\
\hline
\end{tabular}


History of drinking

Yes

No

Place of residence

Countryside

Cities and towns

hs-CRP (mg/l)

Lp-PLA2 (mg/l)

Treatment methods

Propranolol therapy

Metoprolol therapy
98

40

78

60

138

138

$73(96.05)$

48 (77.42)

$39(97.50)$

$53(83.93)$
5.028

0.025

$82(83.67) \quad 16(16.33)$

$1(2.50)$

0.042

0.838

$68(13.04) \quad 10(13.04)$

7 (16.07)

31.09

$<0.001$

$7.62 \pm 1.41$

35.44

$<0.001$

$389 \pm 28.10$

24.48

$<0.001$

TABLE 5: LOGISTIC MULTIVARIATE REGRESSION ANALYSIS ASSIGNMENT

\begin{tabular}{lcc}
\hline Factor & Variable & Assignment \\
\hline Gender & X1 & Male=0, female=1 \\
History of diabetes & X2 & No=0, yes=1 \\
History of hypertension & X3 & No=0, yes=1 \\
History of smoking & X4 & No, yes=1 \\
History of drinking & X5 & No, yes=1 \\
hs-CRP $(\mathrm{mg} / \mathrm{l})$ & X6 & The data belong to continuous variables and are analyzed with original data. \\
Lp-PLA2 $(\mathrm{mg} / \mathrm{l})$ & $\mathrm{X} 7$ & The data belong to continuous variables and are analyzed with original data. \\
Treatment methods & Propranolol treatment=0, metoprolol treatment=1
\end{tabular}

TABLE 6: MULTIVARIATE LOGISTIC REGRESSION ANALYSIS ON EFFICACY OF UAP PATIENTS

\begin{tabular}{|c|c|c|c|c|c|c|}
\hline Variable & B & S.E & Wals & $\mathbf{P}$ & OR & $95 \% \mathrm{Cl}$ \\
\hline Gender & 1.104 & 0.462 & 5.238 & 0.013 & 2.241 & $1.241-6.122$ \\
\hline $\begin{array}{l}\text { History of } \\
\text { diabetes }\end{array}$ & 1.897 & 0.654 & 5.212 & 0.026 & 1.122 & $0.532-2.373$ \\
\hline $\begin{array}{l}\text { History of } \\
\text { hypertension }\end{array}$ & 2.016 & 0.759 & 6.971 & 0.029 & 1.582 & $1.124-2.448$ \\
\hline $\begin{array}{l}\text { History of } \\
\text { smoking }\end{array}$ & 0.133 & 0.042 & 3.684 & 0.951 & 0.492 & $0.165-1.284$ \\
\hline $\begin{array}{l}\text { History of } \\
\text { drinking }\end{array}$ & 0.348 & 0.118 & 9.985 & 0.640 & 1.143 & $0.365-4.261$ \\
\hline hs-CRP (mg/l) & 1.171 & 0.517 & 4.778 & 0.010 & 3.171 & $1.561-6.352$ \\
\hline Lp-PLA2 (mg/l) & 1.249 & 0.567 & 5.123 & 0.016 & 3.204 & $1.607-6.398$ \\
\hline $\begin{array}{l}\text { Treatment } \\
\text { methods }\end{array}$ & 2.355 & 0.988 & 5.318 & 0.007 & 5.433 & $2.717-10.836$ \\
\hline
\end{tabular}


Coronary atherosclerotic heart disease (coronary heart disease) is a frequently-occurring and familiar disease in the cardiovascular system with high morbidity and mortality ${ }^{[21]}$. Its main pathogenesis is related to coronary atherosclerosis ${ }^{[22]}$. UAP, as one of the most serious syndromes of coronary heart disease, is mainly caused by imbalance of blood supply and oxygen supply in coronary artery. Due to the unstable condition, easy development and rapid progression of UAP, although current studies show that drug therapy and non-drug therapy can reduce its mortality, they still cannot better quality of life and prognosis clinically ${ }^{[23]}$. The disease characteristics of UAP are mainly tied to its pathogenesis. UAP's pathogenesis is relatively complex, but the current research shows that most of them are due to sudden rupture of atherosclerotic plaques in blood vessels. Plaque after rupture rapidly forms thrombus, further blocking the original narrow arterial blood vessels and aggravating the degree of ischemia and hypoxia ${ }^{[24]}$. With the acceleration of globalization and social development, the living standard is continuously improving. However, it is obvious that the increasing pace of life and the sharp increase in living pressure have led to the rising morbidity of UAP. If UAP patients do not receive timely and effective treatment, it is very easy to cause acute myocardial infarction or ischemic sudden death. Hence, it's quite significant to study its safe and effective medication scheme for clinical selection of therapeutic measures ${ }^{[25]}$.

Previous clinical studies have reported many therapeutic methods and effects of UAP. For example, Gaziano et $a l^{[26]}$ pointed out that aspirin, as the antithrombotic therapy with the highest drug usage rate, could effectively prevent platelet aggregation and play an antithrombotic role. It can significantly reduce the mortality of UAP and the incidence of AMI and has been clinically used as a conventional treatment drug. Murdoch et al. ${ }^{[27]}$ also reported that nitroglycerin could expand arterial blood vessels to increase blood supply and oxygen supply of myocardium, reducing the symptoms of UAP and the incidence of worsening cardiovascular events effectively. At the same time, Gottlieb et al. ${ }^{[28]}$ pointed out that treating UAP with propranolol could obviously improve the anoxic state by blocking $\beta 1$ and $\beta 2$ receptors on the heart, antagonizing the excitation of sympathetic nerve, inhibiting the action of catecholamine, and reducing the oxygen consumption of myocardium. However, Prieto et $a .^{[29]}$ studied that after metoprolol was taken by UAP patients, it selectively acted on $\beta 1$ receptor of the heart, effectively improving myocardial ischemia and coronary blood flow without affecting muscle blood supply during exercise, thus being significantly superior to propranolol in clinical efficacy and having better exercise tolerance. In this study, the total effective rate of the observation group was $96.05 \%$ and that of the control group was $77.42 \%$. The observation group was obviously superior to the control group. The incidence of adverse reactions after treatment was relatively low and there was no remarkable difference between the two groups, which indicated that metoprolol had better clinical efficacy in treating UAP than propranolol. Simultaneously, the seizure frequency and duration of angina pectoris in patients of both groups were improved after treatment and the frequency and duration in the observation group decreased more dramatically, indicating that metoprolol could better control the onset of angina pectoris and relieve clinical symptoms than propranolol. Some studies have shown that $\beta$ receptor blockers can improve cardiac function by acting on $\beta$ receptors on the heart during the treatment of $\mathrm{UAP}^{[30]}$. In this study, cardiac function in the observation group improved better than that in the control group, indicating that metoprolol had more selective action on myocardial cells to improve the cardiac function of patients.

The development and progression of UAP are relevant to the pathological changes of atherosclerosis. A large number of studies believe that inflammatory reactions always occur and play a crucial part in the process of atherosclerosis ${ }^{[31]}$. Stefanadis et al. clarified that the levels of inflammatory factors hs-CRP and Lp-PLA2 were highly expressed in UAP patients, and the plasma concentration was significantly increased. The increase indicated the instability of atherosclerotic plaque, which would increase the risk of malignant cardiovascular events $^{[32]}$. Lp-PLA2 is a highly specific inflammatory factor related to the vulnerability of atherosclerotic plaques and can be used as an independent risk factor for cardiovascular events. Thus, we measured the serum inflammatory factor level of UAP patients. And the results showed that the hs-CRP and Lp-PLA2 levels in both groups decreased after treatment, and the decrease in the observation group was more remarkable, indicating that metoprolol was more effective than propranolol in inhibiting inflammatory response. Finally, we analyzed the risk factors and found that hs-CRP and Lp-PLA2 levels, gender, diabetes history, hypertension history and treatment methods before treatment were independent risk factors affecting the efficacy of UAP patients. Ognev et al. ${ }^{[33]}$ pointed out that history of hypertension, diabetes and gender were 
the main risk factors for UAP.

To sum up, compared with propranolol, metoprolol can better improve the development and progression of UAP, perfect patients' heart functions and reduces the level of inflammatory factors. However, there is still room for improvement. For example, we can supplement the basic experiments of the therapeutic mechanism of the two therapeutic methods and explore the risk factors affecting the efficacy of patients from the molecular level. In addition, we can also analyze their cognitive function and quality of life not observed in this research. Furthermore, the sample size can be increased to enhance the verification of the study.

\section{Funding:}

Effects of macrophage polarization mediated via beta 2 receptor on ox-LDL-induced macrophage charring, Scientific Research Projects of Hubei Health and Health Commission from 2019 to 2020, (WJ2019F073); Effect of propranolol on LP-PLA2 and HsCRp in patients with unstable angina pectoris, Science Foundation of Three Gorges University (KJ2015A028).

\section{Conflict of interests:}

The authors declared no conflicts of interest.

\section{REFERENCES}

1. D'Souza M, Sarkisian L, Saaby L, Poulsen TS, Gerke O, Larsen TB, et al. Diagnosis of unstable angina pectoris has declined markedly with the advent of more sensitive troponin assays. Am J Med 2015;128(8):852-60.

2. Giannitsis E, Biener M, Hund H, Mueller-Hennessen M, Vafaie $\mathrm{M}$, Gandowitz J, et al. Management and outcomes of patients with unstable angina with undetectable, normal or intermediate hsTnT levels. Clin Res Cardiol 2020;109(4):476-87.

3. Yao W, Gao Y, Wan Z. Serum metabolomics profiling to identify biomarkers for unstable angina. Biomed Res Int 2017;2017.

4. Ozaydin M, Yucel H, Kocyigit S, Adali MK, Aksoy F, Kahraman F, et al. Nebivolol versus carvedilol or metoprolol in patients presenting with acute myocardial infarction complicated by left ventricular dysfunction. Med Princ Pract 2016;25(4):316-22.

5. Sami S, Willerson JT. Contemporary treatment of unstable angina and non-ST-segment-elevation myocardial infarction (part 2). Tex Heart Inst J 2010;37(3):262-75.

6. Yang L, Song L, Ma D, Zhang J, Xie H, Wu H, et al. Plasma S100A4 level and cardiovascular risk in patients with unstable angina pectoris. Biomark Med 2019;13(17):1459-67.

7. Wu SW, Pan Q, Chen T, Wei LY, Xuan Y, Wang Q, et al. Research of medical expenditure among inpatients with unstable angina pectoris in a single center. Chin Med J 2017;130(13):1529.

8. Al-Majed AA, Bakheit AHH, Abdel Aziz HA, Alajmi FM, AlRabiah H. Propranolol. Profiles Drug Subst Excip Relat Methodol 2017;42:287-338.
9. Batra S, Bhushan R. Methods and approaches for determination and enantioseparation of (RS)-propranolol. Biomed Chromatogr 2019;33(1):e4370.

10. Bykov K, Gagne JJ, Wang B, Choudhry NK. Impact of a Metoprolol Extended Release Shortage on PostMyocardial Infarction $\beta$-Blocker Utilization, Adherence and Rehospitalization. Circ Cardiovasc Qual Outcomes 2018;11(10):e004096.

11. Rossi P, Paoli P, Chelazzi L, Conti L, Bencini A. The solidstate structure of the $\beta$-blocker metoprolol: A combined experimental and in silico investigation. Acta Crystallogr C Struct Chem 2019;75(2):87-96.

12. Allam A, Fetih G. Sublingual fast dissolving niosomal films for enhanced bioavailability and prolonged effect of metoprolol tartrate. Drug Des Devel Ther 2016;10:2421-33.

13. Sertić J, Skorić B, Lovrić J, Bozina T, Reiner Z. Does Lp-PLA2 determination help predict atherosclerosis and cardiocerebrovascular disease?. Acta Med Croatica 2010;64(4):237-45.

14. Mitevska I, Srbinovska E, Stojanovska L, Antova E, Apostolopoulos V, Bosevski M. Single-photon emission computed tomography myocardial ischemia detection in highrisk asymptomatic patients: correlation with coronary calcium score and high-sensitivity C-reactive protein. Indian J Nucl Med 2019;34(2):99.

15. Yang F, Ma L, Zhang L, Wang Y, Zhao C, Zhu W, et al. Association between serum lipoprotein-associated phospholipase A2, ischemic modified albumin and acute coronary syndrome: a cross-sectional study. Heart Vessel 2019;34(10):1608-14.

16. Ma CY, Xu ZY, Wang SP, Peng HY, Liu F, Liu JH, et al. Change of inflammatory factors in patients with acute coronary syndrome. Chin Med J 2018;131(12):1444-49.

17. Zhong Y, Ye F, You W, Wu ZM. Correlation between serum inflammatory cytokine levels and fibrous cap thickness of fibrofatty plaque in coronary culprit lesions. Zhonghua Xin Xue Guan Bing Za Zhi 2017;45(7):566-71.

18. January CT, Wann LS, Calkins H, Chen LY, Cigarroa JE, Cleveland JC, et al. 2019 AHA/ACC/HRS focused update of the 2014 AHA/ACC/HRS guideline for the management of patients with atrial fibrillation: a report of the American College of Cardiology/American Heart Association Task Force on Clinical Practice Guidelines and the Heart Rhythm Society. J Am Coll Cardiol 2019;74(1):104-32.

19. Cleophas TJ, van't Leven M, Kauw FH, Remmert HP, Kuijper A, Zwinderman K, et al. Celiprolol vs. propranolol in unstable angina pectoris: a double-blind, randomized, parallel-group study. Angiology 1995;46(2):137-44.

20. Bhat MA, Gandhi G. Assessment of DNA damage in leukocytes of patients with coronary artery disease by comet assay. Int Heart J 2017;58(2):271-4.

21. Ahmadi A, Leipsic J, Blankstein R, Taylor C, Hecht H, Stone $\mathrm{GW}$, et al. Do plaques rapidly progress prior to myocardial infarction? The interplay between plaque vulnerability and progression. Circ Res 2015;117(1):99-104.

22. Pasterkamp G, Den Ruijter HM, Libby P. Temporal shifts in clinical presentation and underlying mechanisms of atherosclerotic disease. Nat Rev Cardiol 2017;14(1):21-9.

23. Sikora J, Niezgoda P, Barańska M, Buszko K, Skibińska N, Sroka W, et al. METoclopramide Administration as a Strategy to Overcome MORPHine-ticagrelOr Interaction in PatientS with Unstable Angina PectorIS - the METAMORPHOSIS trial. Thromb Haemost 2018;118(12):2126-33. 
24. Sakaguchi M, Ehara S, Hasegawa T, Matsumoto K, Nishimura $\mathrm{S}$, Yoshikawa $\mathrm{J}$, et al. Coronary plaque rupture with subsequent thrombosis typifies the culprit lesion of non-ST-segmentelevation myocardial infarction, not unstable angina: nonST-segment-elevation acute coronary syndrome study. Heart Vessels 2017;32(3):241-51.

25. Tegn N, Abdelnoor M, Aaberge L, Endresen K, Smith P, Aakhus $\mathrm{S}$, et al. Invasive versus conservative strategy in patients aged 80 years or older with non-ST-elevation myocardial infarction or unstable angina pectoris (After Eighty study): an open-label randomised controlled trial. Lancet 2016;387(10023):1057-65.

26. Gaziano JM, Brotons C, Coppolecchia R, Cricelli C, Darius $\mathrm{H}$, Gorelick PB, et al. Use of aspirin to reduce risk of initial vascular events in patients at moderate risk of cardiovascular disease (ARRIVE): a randomised, double-blind, placebocontrolled trial. Lancet 2018;392(10152):1036-46.

27. Murdoch D, Dhillon P, Niranjan S. Recurrent myocardial infarction secondary to Prinzmetal's variant angina. Singapore Med J 2015;56(5):e74-7.

28. Gottlieb SO, Weisfeldt ML, Ouyang PA, Achuff SC, Baughman KL, Traill TA, et al. Effect of the addition of propranolol to therapy with nifedipine for unstable angina pectoris: a randomized, double-blind, placebo-controlled trial. Circulation 1986;73(2):331-7.
29. García-Prieto J, Villena-Gutiérrez R, Gómez M, Bernardo E, Pun-García A, García-Lunar I, et al. Neutrophil stunning by metoprolol reduces infarct size. Nat Commun 2017;8(1):1-5.

30. Li YF, Li WH, Li ZP, Feng XH, Xu WX, Chen SM, et al. Left atrial area index predicts adverse cardiovascular events in patients with unstable angina pectoris. J Geriatr Cardiol 2016;13(8):652-7.

31. Crea F, Libby P. Acute coronary syndromes: the way forward from mechanisms to precision treatment. Circulation 2017;136(12):1155-66.

32. Stefanadis C, Antoniou CK, Tsiachris D, Pietri P. Coronary atherosclerotic vulnerable plaque: current perspectives. J Am Heart Assoc 2017;6(3):e005543.

33. Ognev VA, Podpriadova AA, Lisova AV. Identification and assessment of risk factors role in myocardial infarction development. Wiad Lek 2019;72:779-83.

This is an open access article distributed under the terms of the Creative Commons Attribution-NonCommercial-ShareAlike 3.0 License, which allows others to remix, tweak, and build upon the work non-commercially, as long as the author is credited and the new creations are licensed under the identical terms

This article was originally published in a special issue,
"Diagnostic and Therapeutic Advances in Biomedical Research
and Pharmaceutical Sciences"
Indian J Pharm Sci 2021:83(5) spl issue "75-84"

